\title{
perifèria
}

Número 15, diciembre 2011

www.periferia.name

\section{A estratégia e seus outros: notas sobre o Fórum Social Mundial.}

\author{
Julia Ruiz Di Giovanni - Universidade de São Paulo
}

\section{Resumo}

Este artigo tem como objeto questões metodológicas implicadas na análise da noção de estratégia no contexto de realização do Fórum Social Mundial (FSM) entre 2001 e 2005, tema de pesquisa de doutorado em curso junto ao Programa de PósGraduação em Antropologia Social da USP. Trata-se de uma noção comum entre militância, crítica engajada e análise acadêmica, recorrente na produção de enunciados que buscam definir o que o FSM é e para que ele serve, que traça mapas e itinerários neste amplo universo político. A análise explora os usos da noção nos textos programáticos e de análise produzidos por participantes e organizadores do Fórum Social Mundial. As tensões identificadas a partir de diferentes modos de enunciação da estratégia, permitem colocar em discussão o deslocamento de conceitos políticos em jogo no contexto do Fórum Social Mundial, sua temporalidade e historicidade particulares.

Palavras-chave: Forum Social Mundial, estratégia, movimentos sociais, etnografia, teoria política.

\begin{abstract}
This article presents some questions raised from the analysis of the notion of strategy in the context of the World Social Forum (WSF) between 2001 and 2005 object to a research being developed by the author in the University of São Paulo Graduate Studies in Social Anthropology Program. The notion is considered in its circulation accross the boundaries between activism, engaged criticism and scholar analysis, particularly as it is used for in definitions of what the WSF is and what it is for, as participants, organizers and analysts draw maps and itineraries trough the broad Forum semantic and political universe. The consideration of the tensions made sensible in the different ways of enouncing strategy allows us to raise questions on the change of political concepts within the WSF, focusing particular relations of temporality and historicity.
\end{abstract}

Keywords: World Social Forum, strategy, social movements, ethnography, political theory.

\footnotetext{
${ }^{1}$ Doutoranda do Programa de Antropologia Social, Departamento de Antropologia - USP; bolsista da Fundação de Amparo à Pesquisa do Estado de São Paulo (FAPESP). Enviar correspondência a: juliaruiz@usp.br.
} 


\section{perifèria}

Número 15, diciembre 2011

www.periferia.name

O Fórum Social Mundial (FSM), conhecido evento de encontro e debate de organizações de esquerda, reúne Ongs, movimentos sociais e outras associações. Seu lema: "Um outro Mundo é Possível", enuncia sua oposição à hegemonia de um paradigma social, político e econômico dito neoliberal, tanto em escala local quanto nacional e internacional. Volto como pesquisadora, a um universo do qual participei intensamente como militante no período de 2000 a 2006, buscando estabelecer condições de análise do FSM como experiência da política e como lugar de produção e tensionamento de historicidades particulares.

Segundo diferentes interpretações os grandes protestos antiglobalização, os Encuentros Intergalácticos convocados pelo Exército Zapatista de Libertação Nacional e o fóruns de ONGs paralelos às conferências mundiais da Nações Unidas teriam constituído os antecedentes mais diretos do Fórum Social Mundial, no que diz respeito a experiências internacionais de encontros militantes, entre organizações e ativistas mobilizados por leituras de mundo e reivindicações comuns. No entanto, em termos da diversidade dos grupos e movimentos reunidos, de suas formas, demandas, temas de mobilização, modos de ação e organização, bem como de seu alcance cultural e geográfico, o Fórum Social Mundial parece não encontrar precedentes (Conway 2008). Quase sempre enfaticamente, o FSM é pensado por organizadores, participantes, mas também por comentadores acadêmicos, como uma forma política nova, para a qual as definições e explicações ainda não foram encontradas - um "objeto político não-identificado" ${ }^{2}$ (Courtin 2007).

O Fórum Social Mundial não é referido apenas como um tipo de evento ou série de encontros intermitentes, mas também como uma atividade contínua, em que pessoas e grupos se encontram permanentemente engajados. É muito comum ainda, embora seja amplamente rechaçada a definição do FSM como um "ator político", que diversos autores escrevam sobre o Fórum como um verdadeiro sujeito, dotado de corpo, alma, e vontade - "o Fórum opta", "o Fórum precisa"

\footnotetext{
${ }^{2}$ Todas as citações foram traduzidas por mim.
} 


\section{perifèria}

Número 15, diciembre 2011

www.periferia.name

(Teivanen 2009:94). A necessidade de distanciamento e análise quanto a este sentido de unidade e engajamento motivou as reflexões que apresento a seguir.

A jornalista Naomi Klein registra uma imagem ao final do primeiro encontro do FSM:

Um fato talvez não incomum no encerramento de um encontro assim me pareceu digno de nota: um casal no avião, que estava nos assentos da fileira ao lado da minha, ainda usava seus crachás do Fórum. Era como se eles quisessem permanecer naquele mundo sonhado, ainda que imperfeito, por um tempo um pouco mais longo, antes de se separarem nas conexões para Newark, Paris, Cidade do México, engolidos por um enxame de apressados homens de negócios, sacolas Gucci dos free-shops e notícias da CNN sobre as cotações das bolsas de valores ${ }^{3}$

Se, por um lado, o Fórum Social Mundial consiste em séries de eventos ou convergências temporárias, por outro, consiste em um emaranhado permanente de organização e pertencimento. A complexidade dessa dinâmica é sensível quando observamos o intenso trânsito de sentidos políticos sob as categorias que aparecem nos discursos sobre o Fórum, para designar modos de relação que sobrevivem ao encerramento dos encontros: "rede", "convergência", "articulação", "globalização", "espaço" - termos muitas vezes comuns às linguagens da teoria e da militância. Muitos participantes, sobretudo os organizadores, desde 2001, veem e enunciam o Fórum Social Mundial como lócus de sua atividade política, ou, para usar a imagem que nos oferece Klein, alguns nunca chegam a tirar seus crachás.

Após a realização do primeiro encontro em 2001, foi constituído um Conselho Internacional do Fórum Social Mundial, composto por dezenas de organizações e movimentos sociais, tidos como representativos de lutas anti-neoliberais. Do ponto de vista de sua composição e do seu lugar no processo de tomada de decisões, o Conselho Internacional torna-se uma espécie de âmbito permanente do FSM e referência internacional a que passa a se remeter o Comitê Organizador Brasileiro. É o Conselho Internacional que aprova neste momento a Carta de Princípios,

\footnotetext{
${ }^{3}$ Naomi Klein, 2002.
} 


\section{perifèria}

Número 15, diciembre 2011

www.periferia.name

documento que legitima o Fórum Social Mundial como processo colaborativo, e passa a orientar seus procedimentos daí em diante.

O Fórum Social Mundial de Porto Alegre foi um evento localizado no tempo e no espaço. A partir de agora, na certeza proclamada em Porto Alegre de que "um outro mundo é possível", ele se torna um processo permanente de busca e construção de alternativas, que não se reduz aos eventos em que se apoie (FSM 2001).

Ao mesmo tempo em que define fronteiras e orienta procedimentos, a Carta de Princípios e a existência do Conselho que a institui anunciam uma unidade do Fórum Social Mundial que ultrapassa o sentido do evento anual e torna a ciência dessa ultrapassagem condição necessária de integração "a ser respeitada por tod@s que queiram participar desse processo e organizar novas edições do Fórum Social Mundial" (FSM 2001).

O "processo permanente" do Fórum Social Mundial definido na Carta, se torna um princípio sobreposto às unidades de sua realização como evento anual (FSM 2001, FSM 2002, 2003 e assim por diante). É nesse sentido que o presente trabalho se refere ao "Fórum" no singular, quando não aos Fóruns tomados como eventos particulares ainda que não independentes.

Ressalto a importância desse objeto textual, a Carta - referência permanente da "unidade de diversos" do Fórum Social Mundial e de sua almejada estabilidade temporal, a qual se atribui precedência sobre a mobilização intermitente dos eventos anuais. De fato, a palavra escrita - publicada na Internet ou em papel, como material oficial, em artigos de opinião ou artigos acadêmicos, informes em pequenas publicações de organizações participantes - ocupa espaço fundamental na constituição do que o Fórum Social Mundial é. A secção "Memória do FSM" do site oficial, por exemplo, é inteiramente composta de textos: análises e balanços. Chamo de análises e balanços, textos descritivos, programáticos e críticos, sobre o Fórum Social Mundial, produzidos por autores intelectual e politicamente mobilizados por diferentes experiências de participação.

Michael Albert escreve em seu balanço do FSM, de 2002: "Foi exaustivo, sem fronteiras, sem pontos finais" (Albert 2002:2011). Introduzir pontuação, ênfases e 


\section{perifèria}

Número 15, diciembre 2011

www.periferia.name

cadência é precisamente o que está em jogo nesse corpo de textos. Eles interpretam fatos e discursos, associam ideias, constroem perspectivas de análise, julgam, classificam, nomeiam impasses. Alguns autores são intelectuais conhecidos; outros, conhecidos apenas no universo do FSM; outros ainda não aparecem em bibliografias, existindo por meio de designações coletivas, ou permanecendo voluntariamente anônimos. Como militante da Marcha Mundial das Mulheres, eu mesma contribuí com essa produção: além de ter colaborado com a elaboração de documentos coletivos e anônimos, publiquei dois textos assinados sobre o Fórum Social Mundial: um artigo para o dossiê da Revista De Estudos Feministas, e, mais tarde, o artigo "Después de Mumbai", publicado na coletânea Mumbai - Foro Social Mundial 2004 editado pela ativista e escritora Esther Vivas.

Estes textos têm em comum o fato de terem sido concebidos por seus produtores como parte de um "processo fórum"; expressão frequente, que designa o conjunto de eventos e ações preparatórias envolvidos no FSM como totalidade dinâmica, constante e em evolução, por oposição à noção do "fórum evento", entendido como acontecimento esporádico.

Sob inspiração de Michel de Certeau (1980), é possível dizer que, do ponto de vista do engajamento dos autores e da noção processual que os orienta, escrever para o Fórum e escrever $o$ Fórum são movimentos quase indistintos. As categorias pelas quais os textos de análise enunciam as experiências coletivas são inseparáveis da constituição do Fórum Social como acontecimento político e histórico. O "Fórum processo" designa assim uma densa formação de modos de narrativa e descrição, espacializações, temporalizações e segmentações político semânticas. Nesse contexto, os enunciados de análise e balanços são verdadeiros acontecimentos.

Entre os artigos reunidos em publicações a que tive acesso, e levando em conta sua ampla variedade de tons e temáticas, é raríssimo encontrar análises que soem distanciadas de seu objeto ou que não sejam tocadas, ainda que sutilmente, por alguma urgência militante. Em 2005, a Ephemera, revista independente sobre "teoria em política e organização", apoiada pela escola de Administração e Negócios da Universidade de Londres, dedicou um número aos Fóruns Sociais. No editorial, 


\section{perifèria}

Número 15, diciembre 2011

www.periferia.name

os organizadores, Böhm, Sullivan e Reyes, atribuem sentido forte ao engajamento dos textos que apresentam ao público:

uma vez que a política desse movimento é uma que objetiva a transformação da vida enquanto tal, as contribuições [...] não são meras representações: ao contrário, são intervenções ontológicas em um projeto político da transformação radical do ser (Böhn, Sullivan, Reyes 2005:99).

Aqui também a produção e publicação dos textos não se separa, segundo os autores, de seu engajamento "ontológico". Nesse sentido, o mesmo texto define o FSM como uma referência magnética da "cultura política crítica" da década passada.

\section{A estratégia - categoria "nativa"}

Em parte da minha pesquisa, tomei os textos de análise e balanço como um conjunto de fontes primárias para a descrição e problematização de alguns alinhamentos produzidos nessa espécie de campo magnético do Fórum Social Mundial. Procurei inicialmente destacar certos termos recorrentes e seus usos pelos autores em textos de posicionamento público, que gravitam em torno das discussões estabelecidas no Conselho Internacional do Fórum, considerado a instância máxima de decisão e funcionamento internacional.

Os textos selecionados foram produzidos em nome de organizações e representantes integrantes do Conselho; colaboradores eventuais; pessoas ligadas a coletivos, organizações e movimentos participantes (ou mobilizadas por seu envolvimento político pessoal) ou ainda militantes e intelectuais interessados nas temáticas internas do Conselho. De uma forma ou de outra, foram publicados com vistas a intervir nos debates, formar opiniões, propagar e sintetizar os argumentos que constituem aquilo que Boaventura de Souza Santos chama de "movimento utópico e epistemológico" do próprio Fórum (Santos 2005:15).

Mais do que transcrever a partir destes documentos a geometria e os encaixes de uma instância institucional - o Conselho Internacional (CI) do FSM - e seus mecanismos decisórios, interessa observar como essas formulações de intervenção, mesmo diferentes entre si, constituem um "modo de fazer". Aqui recorro mais uma 


\section{perifèria}

Número 15, diciembre 2011

www.periferia.name

vez a De Certeau, tomando emprestada a expressão que aparece $A$ Invenção do Cotidiano (1980) para destacar a complexidade - ontológica, epistemológica e utópica, como indicam os próprios autores - dos discursos analíticos produzidos no âmbito do FSM. Para além do traçado de uma rede de relações, os enunciados que gravitam em torno do CI podem ser analisados do ponto de vista da experiência política particular do FSM, como um "modo de fazer" parte dele.

As primeiras leituras e contatos retomados com participantes, organizadores e intérpretes foram marcados pela recorrência da noção de estratégia, que aparece com notável diversidade de nuances, para atribuir ao FSM um sentido de continuidade e permanência. O seu interesse reside na forma como articula, em diferentes níveis, não necessariamente coerentes entre si, a constituição do FSM como uma totalidade - processual, espacial ou cronológica - permitindo tatear o conjunto vastíssimo de enunciados, "modos de dizer" e "modos de fazer" que dele participam.

Trata-se de um conceito complexo, quase nunca problematizado pela bibliografia e empregado em contextos distintos com sentidos diversos, servindo para amarrar séries de questões, validar ou condenar procedimentos, fundar desavenças ou alianças. Evidentemente não estamos falando de um conceito nascido ontem, nem no Fórum Social Mundial: ele possui uma longa história, é povoado de significados mais ou menos assentados em camadas sobrepostas. Vale observar ainda que, em uma situação política multifacetada e resistente a definições cabais como a do FSM, quanto mais se fala em estratégia, mais difícil é saber de que se trata.

Tão difundida quanto difícil de definir, a estratégia acabou por se tornar um dos enigmas que acompanham todo percurso deste trabalho. O problema, antes de mais nada, serviu como instância reflexiva que permite manter em foco a tensão metodológica de fundo da pesquisa: minha posição como pesquisadora é inseparável das relações políticas e afetivas resultantes de uma atuação como ativista ao longo dos primeiros cinco anos do Fórum Social Mundial. A noção de estratégia coloca em movimento essa tensão: não é apenas uma figura comum do discurso militante, mas também uma categoria fundamental às teorias da política que informam as referências acadêmicas da pesquisa - é um conceito que nunca 


\section{perifèria}

Número 15, diciembre 2011

www.periferia.name

deixa de oscilar entre categoria nativa e operador teórico. Um olhar atento sobre os usos da noção de estratégia nas análises e balanços revela como definições políticas no campo do FSM têm sido construídas igualmente por acadêmicos e militantes, cujas formulações se contaminam mutuamente, o tempo todo. Esta circulação de sentidos define, simultaneamente, um objeto de investigação e uma perspectiva de análise.

A escolha deste caminho de espelhamentos confronta o gesto analítico próprio do pesquisador com outros enunciados analíticos, enunciados de outros analistas. Se proponho uma problematização da estratégia como categoria "nativa", uso as aspas para indicar que neste caso o "nativo" é irremediavelmente uma via de mão dupla, em que as categorias da observação se encontram postas em campo e sujeitas aos mesmos usos políticos, estéticos e afetivos, que articulam as formas observadas, e que convidam em ambos sentidos a um exercício de estranhamento.

Mais do que a defesa formal de uma observação participante, esse recurso pretende mostrar um aspecto fundamental dos modos de fazer do e no Fórum Social Mundial: a produção de enunciados (textos, ações, discursos) eminentemente reflexivos, a respeito das próprias formas de fazer política, é a prática mais amplamente reconhecida como característica do FSM, e um dos modos mais visíveis pelos quais uma pessoa ou coletivo pode fazer parte dele. Nesse sentido, Jeffrey Juris (2007), ativista e pesquisador dos movimentos antiglobalização, sustenta que a produção e circulação de análises por parte dos próprios militantes é intensa e constitui uma forma importante de seu ativismo e modo de organização.

Por um ângulo diferente, este aspecto é destacado por Boaventura de Souza Santos, que atribui caráter de "inovação epistemológica" às práticas políticas que o Fórum supostamente inaugura em um diálogo crítico com a face colonial da modernidade" (Santos 2005). Como aponta Janet Conway (2008), esta leitura leva a uma caracterização do FSM como práxis baseada na busca de uma epistemologia autônoma em relação ao pensamento eurocêntrico em que estaria fundado o neoliberalismo. 


\section{perifèria}

Número 15, diciembre 2011

www.periferia.name

Esses poucos exemplos reforçam a percepção de que a produção de enunciados (textos, ações, discursos) a respeito das próprias formas de fazer política, é a prática mais amplamente reconhecida como característica do Fórum Social Mundial. É nesse registro que a estratégia se torna uma chave de leitura possível dos anos de formação do Fórum como unidade processual e institucional. Ela ilumina uma história de generalização de noções ambíguas e particulares que aparecem, seja na voz "própria" do FSM, articulada pela Carta de Princípios (Fórum Social Mundial, 2001) e por outros documentos internos, quanto na construção de chaves teóricas explicativas constituídas nos textos de análise e balanço já referidos. Entre elas, destaco a ideia de "inovação", ou seja a identificação do "Fórum- processo" a uma "nova forma de fazer política".

\section{Lugares de poder e modos de fazer}

A noção de estratégia, em um primeiro nível, articula uma determinada perspectiva da produção engajada das análises e balanços. Está ligada nessa dimensão aos modos de fazer próprios das elaborações generalizantes e teorizantes, aos textos oficiais, à escrita e à palavra dos "intérpretes" do FSM, lideranças, intelectuais e acadêmicos.

Soa sempre familiar, encontrar a palavra estratégia como categoria fundamental da análise política. Ao lado da noção de tática, seus usos remontam à história das revoluções burguesas e proliferam quanto mais as formas da guerra se tornam objeto de estudo e definem um paradigma de compreensão da política. O conceito teria sido difundido entre os militares pela obra de Karl von Clausewitz (1780 1831), autor que, segundo Ernesto Che Guevara, Lênin gostava de citar pela clareza de suas ideias, ainda que se tratasse da análise de um burguês (Guevara 1962:73). De fato, é no período posterior à Revolução Russa que o conceito militar de estratégia passa a figurar em manuais e programas políticos como categoria específica, relativa à luta revolucionária pela tomada do poder político. Ao longo do século $X X$, o conteúdo militar da estratégia, embora reforçado nos contextos de luta armada na América Latina, parece ter se diluído pelos mais diferentes campos da organização social e da ação coletiva. Dos sindicatos às ONGs, passando por sua apropriação concomitante pelo mundo empresarial e pelo marketing publicitário, a 


\section{perifèria}

Número 15, diciembre 2011

www.periferia.name

estratégia permanece associada às funções de eficácia e acúmulo, mas preserva em sua dispersão semântica o antigo nexo bélico da "conquista do objetivo".

No Fórum Social em 2001, o termo não foi incluído no texto Carta de Princípios. Criou-se, no entanto, uma comissão de estratégia do Conselho Internacional do FSM que, tendo evidentemente sofrido várias transformações quanto a sua composição e propósitos, continua em operação até os dias de hoje. O documento "Regras de Funcionamento do CI do FSM", aprovado na reunião do Conselho Internacional de junho de 2003, em Miami, formalizou o funcionamento dessa e de outras comissões ${ }^{4}$. O objeto do trabalho da comissão aparece no plural: trata-se agora de uma "Comissão de estratégias" cuja tarefa é

aprofundar as análises das estratégias, das iniciativas e ações dos agentes do neoliberalismo, bem como das iniciativas dos que se contrapõem à dominação neoliberal (movimento mundial anti ou alter mundialista), visando a facilitar o debate de estratégias de resistência e construção de um outro mundo possível (FSM, 23/07/2003).

Esta é uma das raras passagens dos documentos oficiais em que o funcionamento do Fórum Social Mundial é assinalado em termos de um objetivo comum, e não da "diversidade" de um "espaço aberto". É a "construção de um outro mundo possível", formulação que aspira à unanimidade pela repetição do lema incontestado ("um outro mundo é possível"), que ocupa o lugar do objetivo comum, do qual a "tomada do poder" parece ter sido banida.

É a única passagem neste documento - além daquela que descreve as tarefas de comunicação como "construção de sistemas de informação do processo FSM para além de sua esfera" - a apontar para "fora" do próprio processo fórum, contrapondo os "agentes do neoliberalismo" ao "conjunto de iniciativas dos que se contrapõem à dominação neoliberal". O movimento circular da construção é notável: a tarefa é aprofundar uma análise das estratégias para facilitar o debate sobre estratégias. Examinada segundo o sentido que Ihe atribuíram Clausewitz ou Lênin, a sutileza da definição parece beirar o absurdo.

${ }^{4}$ As comissões mencionadas pelo documento são: Estratégias, Conteúdos, Metodologia, Expansão, Comunicação e Finanças. 


\section{perifèria}

Número 15, diciembre 2011

www.periferia.name

Se uma noção como a de estratégia é chave na concepção do Fórum como unidade, isso certamente não acontece por sua coerência genealógica ou conceitual. Ela aparece aqui sujeita a diferentes usos, porque designa e engendra diferentes modos de relação implicados nessa totalidade. Não se trata apenas de relações políticas preexistentes a serem descritas no contexto Fórum Social Mundial, mas das próprias relações que produzem o Fórum Social Mundial enquanto "contexto" político.

A definição de estratégia apresentada por Michel de Certeau em A Invenção do Cotidiano (1980), pode ser útil para que possamos tornar mais claro este último ponto. "A estratégia", diz ele, postula "um lugar do poder e do querer próprios", postulado que constitui a base da elaboração de "lugares teóricos", sistemas e discursos totalizantes, como no gesto característico da modernidade científica, política ou militar (De Certeau 2007:102). Nesse sentido, poderíamos ver a noção de estratégia no Fórum Social Mundial não apenas como relação entre a ação e um objetivo a ser conquistado, mas também, e fundamentalmente, como uma espécie de fórmula gestual pelo qual efeitos de totalização são constituídos como relações complexas da experiência individual e coletiva e suas expressões no tempo e no espaço.

A Carta de Princípios - e difícil imaginar um objeto mais explicitamente instituinte de um querer e poder próprios do que uma Carta de Princípios - curiosamente indica que o FSM "não se constitui em instância de poder, a ser disputado pelos participantes de seus encontros" (FSM 2001). Assim como na imensa maioria das definições oferecidas nos documentos oficiais, na primeira linha do texto encontramos um segundo componente: "o Fórum Social Mundial é um espaço aberto" (idem).

Como ressalta Janet Conway (2008), a ideia de "espaço" remetia diretamente a seu caráter não deliberativo. Como mencionei anteriormente o FSM, desde seu início, não publica declarações ou assume decisões. Essa interdição é parte do pacto de sua fundação. Isso serviria para garantir que "os participantes encontrem uns aos outros, em vez de competirem por hegemonia sobre o fórum" (Conway 2008:1). Estariam os grupos e movimentos que participam deste processo despidos, 


\section{perifèria}

Número 15, diciembre 2011

\section{www.periferia.name}

portanto, de qualquer sentido estratégico? Se a forma evasiva da definição das tarefas da Comissão de Estratégias parecia querer escapar da definição de um objetivo, o gesto estratégico da Carta de Princípios trata de desfazer o lugar de poder que, segundo a definição de Certeau, deveria constituir.

Segundo vários analistas e comentadores, essa é a própria marca do Fórum Social Mundial. Explicam, por exemplo, Antonio Negri e Michael Hardt, em prefácio ao trabalho de compilação dos documentos do FSM 2002 realizado por Thomas Ponniah e William Fisher:

não é questão de definir um ponto de unidade ou, pior ainda, de identidade, mas simplesmente encontrar o que há de comum em nossas diferenças e expandir o que é comum enquanto nossas diferenças proliferam[...] Cada diferença é um projeto organizacional (Hardt, Negri 2003:Xvii).

Os termos empregados deixam claro: não se trataria assim de uma estratégia como gesto de unificação, mas, ao contrário, de um projeto de proliferação pela diferença. Boaventura de Souza Santos, na passagem sobre "Estratégia e ação política" de seu Manual de Uso do FSM, por sua vez, atribui a novidade do Fórum ao mesmo "minimalismo" da Carta de Princípios:

acesso quase incondicional (só estão excluídos os movimentos ou grupos que advogam a violência); ausência de votações ou deliberações no Fórum enquanto tal; ausência de uma entidade representativa [...] É quase semelhante a uma tábula rasa onde têm lugar todas as formas de luta contra o neoliberalismo [...] aqueles que optam pela auto-exclusão sentem dificuldade em definir com rigor aquilo que os está a excluir (Santos 2005:89-90).

Essa espécie de discurso negativo da estratégia - em que os objetivos são evitados e o lugar de poder comum parece estar em permanente dispersão - minimiza as exclusões e oferece ressonância à recusa de parte de organizadores e simpatizantes de que o FSM seja definido em termos de qualquer objetivo exterior a sua própria reprodução como forma ou como método - a forma de um "espaço aberto", inovação política e epistemológica de que o processo fórum seria portador (Santos, 2005:89-90). Na explicação de Francisco Whitaker "na opção pelo Fórum-comoespaço, esse tipo de organização não deve dirigir aqueles movimentos e 


\section{perifèria}

Número 15, diciembre 2011

www.periferia.name

organizações, mas apenas endossar e apoiar a criação de mais espaços Fórum" (2009:93).

A estratégia do espaço aberto consistiria em manter o "lugar de poder" continuamente esvaziado e o lugar de querer permanentemente aberto a uma pluralidade ilimitada de desejos. A essa tarefa política não estratégica, "de baixa intensidade" e supostamente livre da tradicional epistemologia linear de esquerda, Boaventura de Souza Santos dá o nome de tradução: a produção de inteligibilidade entre experiências presentes e futuras, de todas as partes do mundo, que não deve jamais destruir a identidade daquilo que é traduzido (Santos 2009:384-386). Nessa "babel" alternativa, em vez de serem punidos pela audácia de seu projeto comum a nunca mais poderem falar a mesma língua, os homens podem se entregar ao eterno exercício de linguagens comuns cada vez mais complexas (uma vez que não tem nenhum edifício a projetar e construir).

Assim, chega a parecer uma contradição ter sido o Fórum Social Mundial fundado naquilo que, em certa terminologia política mais convencional, é chamado de "tomada de posição". Lembremos que ele foi concebido com esse título como um evento simultâneo e antagônico à realização anual do Fórum Econômico Mundial em Davos, Suíça. Tratava-se assim de uma espécie de contra evento, como os protestos de Seattle, Praga ou Gênova, realizados em oposição às reuniões oficiais da Organização Mundial do Comércio, do Fundo Monetário Internacional e do G8 (Di Giovanni, 2008). Ainda no calor dessas manifestações antiglobalização, se deu o primeiro Fórum Social Mundial, entre 25 e 30 de janeiro de 2001, na cidade de Porto Alegre, como um primeiro encontro anti-neoliberal mundial, um ritual - que viria a ser periódico - de integração, fortalecimento e renovação de correntes políticas, mas também de seu posicionamento, que se queria contrário às elites transnacionais hegemônicas.

"Pobre parece toda palabra para dar cuenta de esa fabulosa Babel donde, contrariando la parábula bíblica, la tumultuosa diversidad de movimientos, sensibilidades y idiomas compartió ideas y acciones", diriam José Seoane e Emilio 


\section{perifèria}

Número 15, diciembre 2011

www.periferia.name

$\operatorname{Taddei}^{5}(2001: 106)$, em texto publicado no mesmo ano, onde descrevem e comentam os debates diagnósticos e programáticos transcorridos no encontro, tendo como ponto de partida a denúncia da financeirização, da mercantilização, da desregulação e da concentração de poder e riqueza percebidos como estruturantes da globalização capitalista. Os organismos internacionais frente aos quais se davam ainda manifestações massivas de "um movimento global de movimentos", em particular o Banco Mundial, o Fundo Monetário Internacional e a Organização Mundial do Comércio, foram identificados, também no contexto do Fórum, como mecanismos chave de uma estrutura política mundial regida pelos interesses de grandes grupos financeiros e pelas corporações transnacionais (Seoane e Taddei 2001:122).

Durante os "intensos, exaustivos e vibrantes dias" do Fórum Social Mundial, nos termos dos mesmos autores, altas temperaturas, espaços apinhados e ruidosos, e doses generosas de euforia coletiva inspiraram profusa adjetivação, oferecendo aos sentidos as fórmulas materiais da oposição entre uma "La primavera social de Porto Alegre" e o "seleto y mediatizado" parlamento dos capitalistas, funcionários e "gurus globalizadores", que se reuniam simultaneamente no inverno de Davos amparados por um monumental esquema de repressão a manifestações contrárias. O sentido anti-Davos, chegou a ser posto em ação em 2001 através de um confronto via satélite, acompanhado pela torcida local através de telões, que opôs por duas horas uma delegação calculadamente heterogênea de onze representantes do povo reunido na capital gaúcha a quatro senhores brancos de meia idade vestidos em impecáveis ternos de tons sóbrios, alinhados em nome do Fórum de Davos (Seoane e Taddei 2001:121).

É como se diante da nova forma de fazer política que o FSM trazia consigo, tomar posição seria pouco. As exuberantes poéticas da oposição a Davos, são regularmente compensadas pela defesa enfática de que se tratava definitivamente de mais do que uma mera imagem especular do Fórum Econômico. Nas análises e balanços, o Fórum de Porto Alegre, é celebrado como um passo além e positivo

${ }^{5}$ Cientistas sociais argentinos, envolvidos no FSM durante os anos de sua realização em Porto Alegre como representantes do Conselho Latino Americano de Ciências Sociais (CLACSO). 


\section{perifèria}

Número 15, diciembre 2011

www.periferia.name

com relação às grandes manifestações de rua que marcaram o momento político do final da década de 1990 e os primeiros anos do século XXI.

Ignácio Ramonet, diretor do Le Monde Diplomatique - veículo importante de difusão de balanços e análises do FSM - afirma, em 2001, que se trata de um encontro

não para protestar, como em Seattle, Washington, Praga e outros lugares, contra as injustiças, as desigualdades e os desastres que os excessos do neoliberalismo provocam pelo mundo, um pouco em toda parte. Mas sim para tentar, em uma (um) espírito positivo e construtivo dessa vez, propor um quadro teórico e prático que permita conceber uma mundialização de novo tipo e afirmar que um outro mundo menos desumano e mais solidário é possível. (Ramonet 2001).

Na visão de Taddei e Seoane, já mencionados:

Essas propostas que ganharam visibilidade no Fórum não falam apenas da consolidação e legitimidade do movimento antiglobalização neoliberal como uma caixa de ressonância do protesto, mas também como uma experiência de fixar novos horizontes e um programa concreto e realista de transformações econômicas e sociais (Seoane e Taddei, 2001:122).

Se, entre 1999 e 2001, as manifestações às portas das reuniões das instituições internacionais davam a cara dos dissensos políticos antiglobalização, o Fórum Social Mundial, dali em diante se torna a mais conhecida expressão convergente, não apenas dos que estavam contra, mas também dos que estavam trabalhando na formulação de alternativas à dita hegemonia neoliberal. Sob o lema "Um outro mundo é possível", ele define uma nova forma de visibilidade. Se o termo antiglobalização colou-se à imagem dos protestos de rua marcados pelos confrontos entre polícia e manifestantes, ao Fórum Social Mundial aderia mais facilmente o rótulo, de origem francófona, "altermundialista" ${ }^{6}$. A diferença é importante, embora

\footnotetext{
${ }^{6}$ L. Coradini argumenta a respeito da inadequação da noção "altermundialista". Segundo o autor a aplicabilidade da noção no contexto de um evento realizado no Brasil é limitada pelo dado contundente de que, entre os participantes do FSM 2005 apenas lideranças cuja atividade se dá em nível prioritariamente internacional estariam familiarizadas com essa noção ou identificadas a ela. $\mathrm{O}$
} 


\section{perifèria}

Número 15, diciembre 2011

\section{www.periferia.name}

Teivo Teivanen, cientista político finlandês e um dos membros fundadores do Conselho Internacional, tenha razão em advertir que de "anti" a "alter" não está necessariamente implicada uma escala fixa de radicalidades ou esquerdismos.

Embora práticas de protesto tenham feito parte dos encontros da esquerda global em Porto Alegre desde suas primeiras edições ${ }^{7}$, a convocatória para o Fórum, esteve centrada em um plano de amadurecimento intelectual, formulação de críticas e alternativas, cujas formas eram debates, reuniões, "oficinas" ${ }^{8}$ ou seminários, e não as práticas da ação de rua associadas a atitudes de negação e de denúncia.

Se o "espírito" de Seattle tinha a marca inquietante da rebeldia e da ação direta, o espírito de Porto Alegre, nas palavras de Ramonet, surgia como algo mais "construtivo". Taddei e Seoane o descrevem um ponto de chegada e de partida, passagem de um movimento de resistência a um novo estágio afirmativo (2001:123). No mesmo sentido, o documento Histórico do processo FSM - datado de 2 de outubro de 2007, não assinado e disponível no site oficial do escritório/secretaria do Fórum Social Mundial - descreve-o como um espaço internacional para a reflexão e organização "de todos os que se contrapõem à globalização neoliberal e estão construindo alternativas para favorecer 0 desenvolvimento humano e buscar a superação da dominação dos mercados em cada país e nas relações internacionais" (Fórum Social Mundial, 2007).

\footnotetext{
"altermundialismo" aqui, no entanto, refere-se à desconfortável oposição entre "movimento antiglobalização" e altermundialista muito sensível nas duas primeiras edições do FSM.

7 Expressões de protesto e ação direta fazem parte dos Fóruns Sociais Mundiais desde seu início. Em 2001, durante o primeiro FSM e Porto Alegre, um grupo de jovens apontados como punks e anarquistas, contrariando as orientações da organização, tentou ocupar uma loja McDonald's no dia da abertura do evento. Mais tarde, ativistas da Via Campesina, entre os quais o líder antiglobalização francês José Bové, invadiram campos da transnacional de insumos agrícolas Monsanto para protestar contra os produtos transgênicos "em defesa da pequena agricultura" (AGÊNCIA FOLHA, 26.01.2001). No entanto, aspectos de institucionalização e hierarquia, aparecem de forma muito mais pronunciada no Fórum Social Mundial do que nas manifestações de rua. Chegaram a ocorrer, também desde os primeiros anos, protestos dirigidos às próprias contradições internas do Fórum Social Mundial. Em 2002, por exemplo, uma sala com ar condicionado e abastecimento de água mineral, destinada a palestrantes convidados, foi ocupada por um grupo de ativistas durante um protesto festivo cujo lema era "somos todos VIP" (Di Giovanni, 2002, entrevista. In: Cevasco, Leite, Loureiro, 2002).
}

${ }^{8}$ As oficinas costumam designar reuniões menores e participativas, entendidas frequentemente como escape ao formato da audiência passiva encontrado em palestras e conferências. 


\section{perifèria}

Número 15, diciembre 2011

www.periferia.name

\section{Uso e ambivalência do espaço aberto}

Tão importante quanto a noção do espaço-fórum (oposta à dinâmica de disputa de poder), a ideia de uma passagem evolutiva - dos protestos ao espaço de debates sobre alternativas - oferece fundamento e legitimação para a definição de princípios e regras de funcionamento do Fórum, sobre como e quais discursos, práticas e objetos fazem parte deste processo.

O espaço aberto do FSM é um espaço regulado: explicitamente regulado por uma carta de princípios e procedimentos político-administrativos e implicitamente regulado por atribuições de valor e hierarquias. A existência dessas formas de regulação, visíveis e ocultas, está intimamente ligada ao sentido (pro)positivo que Ihe é atribuído, à percepção difundida por diversas análises e balanços de que ele representa um "avanço" com relação às práticas de protesto e oposição (ao neoliberalismo em geral ou ao Fórum de Davos, especificamente) que supostamente o antecederam e que seriam por ele requalificadas.

A forma Fórum Social confere um recorte particular aos problemas da heterogeneidade organizativa, ideológica e geracional que atravessavam as práticas características do movimento antiglobalização (Azzi 2007; Di Giovanni 2008). O motivo que o Fórum Social Mundial mais assumidamente toma emprestado dos protestos antiglobalização é a "unidade na diversidade". No contexto dos protestos de rua, no entanto, este não é um princípio abstrato, mas a forma concreta da ação, uma tática, uma prática coletiva imediata que possibilita, embora não garanta, que deslocamentos comuns - o cerco a uma reunião do Fundo Monetário Internacional ou do G8, por exemplo - sejam compostos por inumeráveis movimentações e gestuais particulares cuja validade e legitimidade não é posta em questão pelo conjunto (Di Giovanni 2008).

No caso do Fórum Social Mundial, a convergência dos diferentes perde seu caráter tático e ganha sentido abstrato: sua matéria não é mais a força dos corpos na rua, e sim o universo de princípios e regulamentos que põem o "espaço aberto" em operação. Na medida em que o Fórum de Porto Alegre é amplamente entendido como um momento distinto do contexto de protesto, falar em "unidade dos diversos" não é apenas uma reiteração, mas uma transformação significativa do 


\section{perifèria}

Número 15, diciembre 2011

www.periferia.name

feixe de tensão e significado que este mote representa. Nos termos de Certeau, ele exprime agora um problema estratégico, próprio da constituição de lugares de poder e de sua projeção no tempo e no espaço.

$\mathrm{Na}$ mesma medida, as regulações internas do FSM produzem aquilo que April Biccum definiu como "ambivalência do espaço aberto". Afirmações contraditórias tais como "o FSM é um espaço aberto" - "partidos políticos não podem participar" ou "o Fórum não é um lugar de poder" - "o Conselho Internacional do Fórum é responsável por orientar realização dos eventos" instauram profunda ambivalência nessa "nova cultura política" que estaria surgindo (Biccum 2005:124).

Um texto de Michael Albert sobre sua experiência no Conselho Internacional do Fórum, levanta perguntas incômodas a respeito dessas contradições: se o Fórum não toma decisões, quem toma as decisões que demarcam os limites práticos e políticos de um processo que envolve centenas, senão milhares, de estruturas organizativas?

E não é que as pessoas na mesa não quisessem uma abordagem mais democrática e participativa. Esse desejo foi expressado várias vezes. Mas depois de algum tempo na reunião, tornou-se óbvio que apesar da estatura e dos desejos dos membros, as pessoas no Conselho e na mesa não eram o lócus real do poder no FSM. [...] Quem decide se vamos ter um evento com a presença de Lula e qual será seu tamanho? E Sobre Castro, ou Chavez? Haverá exclusões? Com base em quê? E os Zapatistas?[...] Qual conteúdo será parte dos eventos centrais e qual conteúdo vai ficar na periferia? Quem vai ter a passagem paga e quem não vai? [...] Qual vai ser a acomodação entre a defesa de uma reforma do sistema capitalista e a defesa de um sistema inteiramente novo? (Albert 2006:364).

Uma reposta fácil seria argumentar que Albert perdeu um número grande de reuniões do Conselho Internacional, ou que ele desconhece a dinâmica interna de trabalho das comissões e a complexidade logística da realização de um megaevento. No entanto, a ausência do lugar de estratégia - ou melhor, uma estratégia de proliferação permanente da diferença, implicaria que todos os assuntos e decisões estivessem em permanente discussão - algo que, na prática, salvo engano, nenhum dos membros do CI defenderia. No momento, destacaremos do relato da participação de Michael Albert apenas a indicação veemente de que o 


\section{perifèria}

Número 15, diciembre 2011

www.periferia.name

espaço aberto do fórum é constituído por uma densa, embora pouco visível, rede de exclusões e gestos de poder eminentemente estratégicos.

A partir das experiências relatadas por Albert e Biccum (2005:122), além da minha própria, parece que um dos efeitos sensíveis dessa ambivalência é o ocultamento dos poderes de decisão e das lógicas particulares que informam as escolhas. A defesa veemente das diferenças internas (tão recorrente na produção de textos do e sobre o FSM) se torna um mecanismo de encobrimento das relações - de poder, certamente - entre os participantes.

Além de articular análises e balanços, em um segundo nível, a estratégia no Fórum Social Mundial aparece como objeto, não da especulação teórica, mas de disputas quanto a decisões consideradas operacionais ou relativas a seu "funcionamento". Seguindo a metáfora sugerida por Whitaker, sendo o fórum-espaço uma "praça", é necessário que haja pessoas e instituições que desempenhem a tarefa de "organizar o uso da praça sem interferir no que está sendo discutido dentro dela" (Whitaker 2009:93).

O problema posto pela separação entre "regras de uso" e "o que está sendo discutido", separação que Whitaker toma como fundamento do FSM, é localizada com precisão pelo artigo crítico de April Biccum. A disposição estratégica não se dá (ao menos em princípio) como cercamento da praça, e sim para estabelecer certa ordem sobre os usos que se pode fazer dela: "o que se torna importante, e aquilo que precisamos manter ter em mente com vigilância é, não apenas que existe um espaço, mas como e para quê o espaço para mobilização e resistência é usado" (Biccum 2005:127). O problema dos usos do espaço permite lançar luz então sobre o universo das escolhas de caráter "operacional" que, em uma espécie de segundo plano, conferem à "nova forma de fazer política" sua margem de manobra. Trata-se dos objetivos e lugares de poder articulados fundamentalmente pelas práticas de organizadores: membros das instâncias de decisão menos visíveis, comissões, comitês e funcionários vinculados à realização dos eventos. É aqui que aparece a hierarquização de temas e participantes, a distribuição de recursos e a distribuição das atividades no espaço, que culmina na transformação da própria noção de estratégia na noção de metodologia. 


\section{perifèria}

Número 15, diciembre 2011

\section{www.periferia.name}

Verifica-se que, no mesmo momento em que se constitui a Comissão de Estratégias, é criada a Comissão de Metodologia do Conselho Internacional, responsável por propor a formulação dos temas estruturantes e o desenho conceitual das atividades do Fórum. Dada a centralidade desta incumbência, esta comissão torna-se permanente, até hoje um dos pontos de articulação mais importantes e palco de alguns dos debates mais acalorados da história do CI que tive oportunidade de acompanhar. Apesar da composição da Comissão não ser fixa, alguns participantes (sempre representantes de entidades membros do CI) permanecem ativos desde o início. Trata-se de fato de uma comissão em que algumas entidades envolvidas na fundação do Fórum no Brasil tiveram papel proeminente9.

A metodologia é entendida como uma "arquitetura do processo Fórum", um desenho estrutural que estabelece o vínculo entre a realização pontual dos eventos no tempo e no espaço e a sobrevivência do FSM enquanto "processo de reflexão estratégica coletiva" (FSM, Comisão de Metodologia 2001). De um ponto de vista crítico, a associação oculta entre a arquitetura metodológica e ordem estratégica do Fórum Social Mundial é formulada também pelos dos organizadores do Acampamento da Juventude - parte do Fórum cujas práticas geraram uma multiplicidade de conflitos com os recortes estabelecidos por outras instâncias (Nunes 2005). A metodologia que ordena espaços centrais e periféricos e autoriza alguns discursos em detrimento de outros, é percebida pelos organizadores do Acampamento (à luz do usos particulares que fazem do espaço do Fórum) como reflexo imediato de uma "lógica de demanda do poder", a exigir a hierarquização de papéis e de lutas, a separação entre causas prioritárias e secundárias, entre a política e as tarefas cotidianas e reprodutivas, aparecendo como um ciclo

\footnotetext{
${ }^{9}$ Organização do primeiro Fórum Social Mundial esteve a cargo de um comitê organizador brasileiro, então formado pela representação nacional da Attac (uma associação de origem europeia pelo controle cidadão das transações financeiras internacionais ligada ao Le Monde Diplomatique), pela Associação Brasileira de ONGs (ABONG), as ONGs Ibase e Cives, a Rede Social de Justiça e Direitos Humanos, a Comissão Brasileira de Justiça e Paz da Congregação Nacional de Bispos do Brasil, a Central Única dos Trabalhadores (CUT) e o Movimento Sem Terra (MST). No período abordado pela pesquisa o comitê esteve vinculado a uma Secretaria Internacional do processo FSM instalada em São Paulo, responsável pela realização dos eventos em Porto Alegre e pelo apoio organizativo às atividades do Conselho Internacional de suas comissões.
} 


\section{perifèria}

Número 15, diciembre 2011

www.periferia.name

aprisionador na fala de um informante que descreve a estratégia como uma "cobra mordendo o próprio rabo".

\section{Sentido da política e suas falhas}

É ainda possível encontrar um terceiro nível de compreensão em que a noção de estratégia aparece articulando a unidade processual do FSM, desta vez para nomear a complexidade implícita das relações de aliança específicas ao campo dos movimentos sociais, que participam do processo tendo em vista prioridades particulares, derivadas de dinâmicas que antecedem e ultrapassam os limites do Fórum Social Mundial.

Como me explicou um militante, a quem perguntei sobre as alianças prioritárias de seu movimento com outros, a estratégia pode ser entendida "como uma cebola". "Vamos por camadas", disse ele. As alianças mais densas e importantes constituem o seu núcleo, em que algo precioso é compartilhado. Neste nível, a noção figura ao lado de outras, como as noções derivadas de aliança estratégica e de confiança, exercendo papel importante na definição de diferentes densidades de relação política, associadas a diferentes graus de afinidade entre grupos e indivíduos participantes do FSM.

Em uma perspectiva etnográfica, como a que busco exercitar aqui, seria impossível localizar um sentido definitivo da noção de estratégia, reduzindo a uma dessas três formas esse termo do qual somos todos em certa medida "nativos". A unidade política que o FSM constitui não é dada pela estratégia pensada apenas como forma homogênea e abrangente da análise política que orienta as ações coletivas a um sentido comum (à maneira do que poderíamos conceber como um "Espírito de Porto Alegre"). Tampouco se trata de uma unidade estabelecida por tábula rasa, em que se dissipam quaisquer relações de poder "velhas" em favor de um mundo político novo em que estaríamos prontos a começar do zero. Finalmente, não seria possível defini-la necessariamente por relações particulares de aliança.

É na medida em que compreende todas essas formas particulares e as relações entre elas, que a estratégia participa da constituição do Fórum Social Mundial como uma unidade processual e espacial, em que é possível engajar-se e reconhecer uma 


\section{perifèria}

Número 15, diciembre 2011

www.periferia.name

certa experiência política. A estratégia aparece aqui como gestual complexo do poder - não como rede de relações positivas a serem descritas numa morfologia, mas como processo dinâmico que engloba a produção de sentidos e suas falhas.

Como conceito e como "gênero" de enunciação, a estratégia articula de maneira geral sentidos da política em termos do que é considerado possível ou eficaz. Essa articulação, no entanto, não é redutível a uma economia de correlação de forças ou disputa de poder simples. Envolve uma complexidade de "modos de dizer" e de "modos de fazer" que são, como vimos, profundamente contraditórios e ao mesmo tempo permeáveis uns aos outros: os discursos do FSM como um sujeito em si, as críticas e apologias dos acadêmicos engajados, a fala cotidiana dos participantes anônimos ou os arranjos operacionais projetados pela secretaria executiva, entre outros fazeres.

A centralidade que atribuo ao gesto estratégico no FSM não anula a consideração analítica de formas "menores" ou táticas, cotidianas e anônimas, cuja apreciação permite sempre alargar a concepção das experiências políticas. Uma etnografia da noção de estratégia no FSM convida ainda a problematizar o uso da distinção entre tática e estratégia proposta por De Certeau como uma dicotomia de termos estanques sob os quais seria possível classificar fragmentos da experiência social. Sugere antes que pensemos estratégia e táticas como modos de fazer, que atualizam a cada momento possibilidades e impossibilidades político-semânticas. No caso da reflexão sobre os textos de análise e balanço que apresentei aqui, é a atenção ao problema da estratégia que nos leva a poder afirmar que os usos de um espaço são politicamente tão ou mais importantes quanto que os princípios de sua fundação.

A noção de "poética social" empregada por Herzfeld para analisar a complexidade das composições simbólicas mobilizadas pelo Estado Nação, amplia esta ideia. Para Herzfeld (2008) a analogia mais precisa para a plasticidade dos significados, que subjaz a toda forma cultural aparentemente fixa, é a poética tal como reconhecida por Jakobson - pensada não como atividade literária específica, mas como função da linguagem que permeia tanto os usos cotidianos como os "excepcionais". Tornar visíveis essas poéticas é uma tarefa crítica que não oculta a mobilidade 


\section{perifèria}

Número 15, diciembre 2011

www.periferia.name

fundamental das relações de significado; apontar seu caráter eminentemente político traz à luz as contradições operantes à sombra de nossas categorias de análise e nos ajuda a expor formas supostamente inapreensíveis da experiência social.

Busquei aqui pensar a experiência política à luz das oscilações, tensões e falhas de uma estratégia sempre perigosamente misturada com seus "outros", como um caminho possível para percorrer a imensa complexidade de poéticas sociais que se constituem e transformam no âmbito do Fórum Social Mundial.

\section{Bibliografía}

Albert, Michael (2002). O Fórum Social Mundial de 2002 e nós. Em: Leite, José Corrêa; Loureiro, Isabel; Cevasco, Maria Elisa (Orgs.). O espírito de Porto Alegre. São Paulo: Paz e Terra.

(2004). "Mumbai, WSF, and Our Futures", disponível no site do FSM: http://www.forumsocialmundial.org.br/dinamic.php?pagina=bal_malbert_2004_ing, data de publicação: 11/02/2004, data de acesso: 20/01/2011.

(2009). WSF: Where to now? Em: Sen e Waterman (Eds.). World Social Forum Challenging Empires. Montréal/Tonawanda/London: Black Rose Books. Böhm, Steffen; Reyes, Oscar; Sullivan, Sian (2005). The organisation and politics of Social Forums. Ephemera: Theory and Politics in Organization, 5(2):98-101, 2005. Disponível em: http://www.ephemeraweb.org/journal/5-2/5-2editorial.pdf.

Cefa, Daniel (2007). Pourquoi se mobilise-t-on? Les théories de l'action collective. Paris: Éditions La Découverte/M.A.U.S.S.

Cevasco, Maria Elisa; Louureiro, Isabel; Leite, José Correa (2002). Apresentação, E O Espírito de Porto Alegre. São Paulo: Paz e Terra.

Conway, Janet (2008). "Decolonizing Knowledge/politics at the World Social Forum", apresentação à International Studies Association, San Francisco. Disponível em: <http://www.allacademic.com/meta/p251415_index.html> . 


\section{perifèria}

Número 15, diciembre 2011

www.periferia.name

Courtin, Christophe (2007). Forum Social Mondial - un objet politique non identifié, Alterinfos - Diffusion de I'Information sur L'Amerique Latine. Segunda-feira, 22 de janeiro de 2007. Disponível em: http://www.alterinfos.org/spip.php?article800, último acesso em fevereiro de 2011.

De Certeau, Michel (1994). L'Invention du quotidien (1980), tome 1: Arts de faire. Folio Essais/Gallimard.

Di Giovanni, Julia Ruiz (2004). Después de Mumbai. Em: Vivas, Esther, Mumbai (Foro Social Mundial 2004) - Balance y Perspectivas de un Movimiento de Movimientos. Barcelona: Icaria.

(2008) Seattle, Praga, Gênova: política anti-globalização pela experiência da ação de rua. São Paulo, Dissertação de mestrado (Programa de Pós Graduação em Antropologia Social), Faculdade de Filosofia Letras e Ciências Humanas - USP. FÓRUM SOCIAL MUNDIAL (2001). Conselho Internacional. "Carta de princípios do Fórum Social Mundial", disponível em:

http://www.forumsocialmundial.org.br/main.php id_menu=4\&cd_language $=1$, data de publicação: 08/06/2002, data de acesso: 26/01/2011.

FÓRUM SOCIAL MUNDIAL (2007). "Histórico do Processo FSM". Disponível em:

http://www.forumsocialmundial.org.br/main.php?id_menu=2\&cd_language $=1$, data de publicação: 2007. Último acesso: janeiro de 2011.

FÓRUM SOCIAL MUNDIAL (2008). Conselho Internacional. "Guía de Princípios para la realización de eventos FSM." Disponível em:

http://www.forumsocialmundial.org.br/noticias_textos.php?cd_news=722, sem data de publicação, data de acesso: 20/01/2011.

Guevara, Ernesto Che (1971). Stratégie et Tactique de la révolution Latinoamericaine (1962), p. 73-86. Em: Fuvres III, Textes politiques. Paris: Maspero.

Harnecker, Marta (2005). Estratégia e Tática. São Paulo: Expressão Popular. 


\section{perifèria}

Número 15, diciembre 2011

www.periferia.name

Hardt, Michael; Negri, Antonio (2003). Foreword. Em: Fischer, William; Ponniah, Thomas. Another World is Possible: Popular Alternative to Globalization at the World Social Forum. London: Zed Books.

Hartog, François (2003). Ordres du Temps, régimes d'historicité e Des îles d'histoire. Em: Régimes d'historicité. Paris: Editions Du Seuil.

Herzfeld, Michael (1997), Intimidade Cultural - Poética Social no Estado Nação, Edições 70, Lisboa, 2008.

Klein, Naomi (2002). Acreditando no fim do fim da história. In: Loureiro, Isabel. Leite, José Correa; Cevasco, Maria Elisa (orgs.). O Espírito de Porto Alegre. São Paulo: Paz e Terra.

Leite, José Corrêa (2003). Fórum Social Mundial: uma invenção política. Em: Fórum Social Mundial, A História de uma Invenção Política. Perseu Abramo, São Paulo, p. $61-90$

Nunes, Rodrigo (2005). The Intercontinental Youth Camp as the Unthought of the World Social Forum. Ephemera: Theory and Politics in Organization, 5(2):277-296. Disponível em http://www.ephemeraweb.org/journal/5-2/5-2nunes1.pdf.

Santos, Boaventura de Souza (2005). O Fórum Social Mundial - Manual de Uso. São Paulo: Editora Cortez.

Teivanen, Teivo (2009). The World Social Forum: Arena or Actor, In: Sen, Waterman; World Social Forum Challenging Empires. Black Rose, 2009, P. 94 103.

Whitaker, Chico (2005). Desafio do Fórum Social Mundial: um Modo de Ver. São Paulo: Edições Loyola. 